This item was submitted to Loughborough's Research Repository by the author.

Items in Figshare are protected by copyright, with all rights reserved, unless otherwise indicated.

\title{
Low-frequency damping of metal panels in ambient air
}

PLEASE CITE THE PUBLISHED VERSION

PUBLISHER

Professional Engineering Publishing / @ IMECHE

VERSION

VoR (Version of Record)

LICENCE

CC BY-NC-ND 4.0

\section{REPOSITORY RECORD}

Walker, S.J.I., G.S. Aglietti, and Paul Cunningham. 2009. "Low-frequency Damping of Metal Panels in Ambient Air". figshare. https://hdl.handle.net/2134/4868. 
This item was submitted to Loughborough's Institutional Repository (https://dspace.lboro.ac.uk/) by the author and is made available under the following Creative Commons Licence conditions.

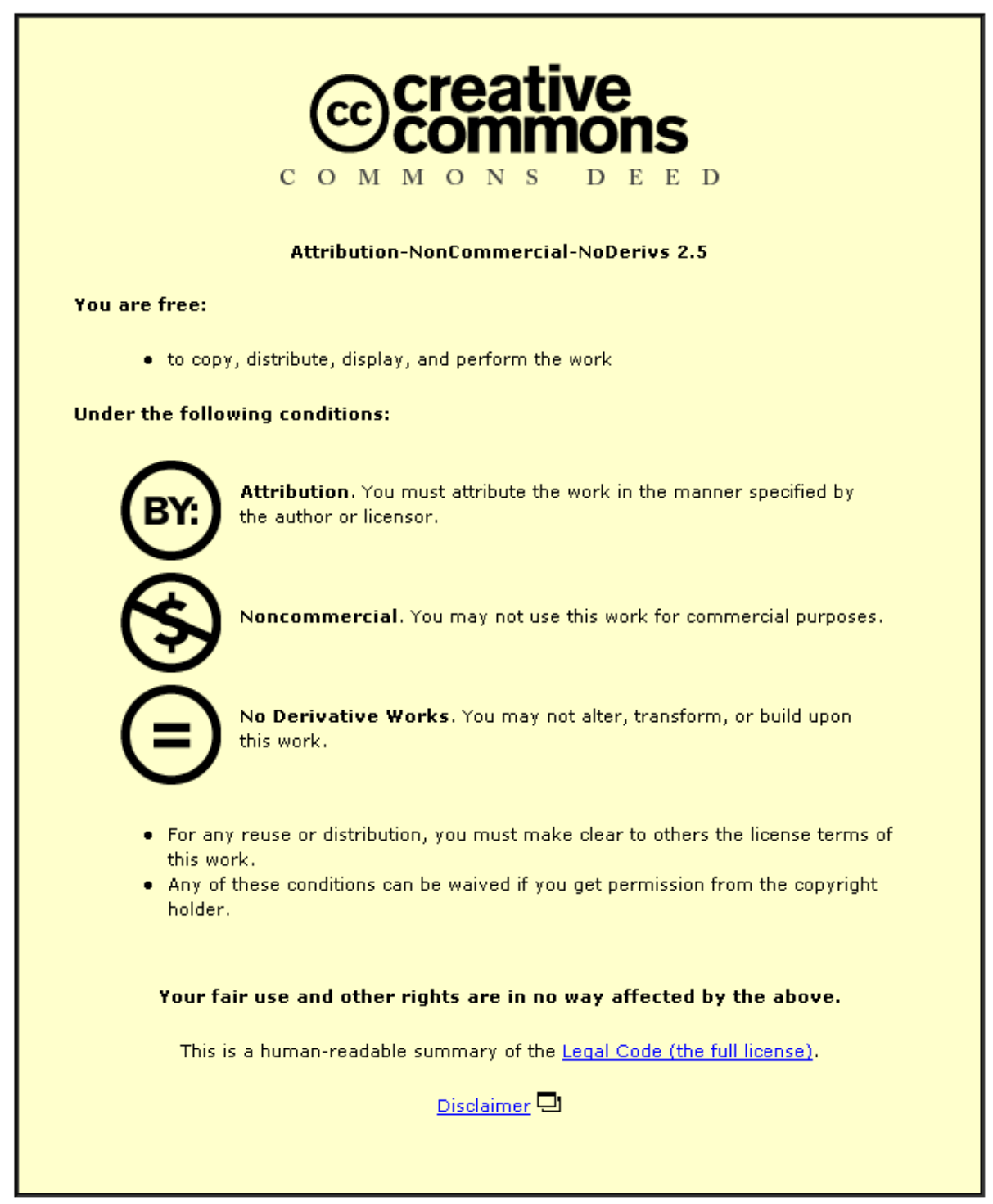

For the full text of this licence, please go to: http://creativecommons.org/licenses/by-nc-nd/2.5/ 


\title{
Low-frequency damping of metal panels in ambient air
}

\author{
S J I Walker ${ }^{1 *}$, G S Aglietti ${ }^{1}$, and P Cunningham ${ }^{2}$ \\ ${ }^{1}$ Astronautics Research Group, University of Southampton, Southampton SO17 1BJ, UK \\ ${ }^{2}$ University of Loughborough, Leicestershire LE11 3TU, UK
}

The manuscript was received on 30 August 2007 and was accepted after revision for publication on 14 March 2008.

DOI: 10.1243/09544062JMES850

\begin{abstract}
Mathematical models of structural dynamics are widely used and applied in many branches of science and engineering, and it has been argued that many of the shortfalls with these models are due to the fact that the physics of joint dynamics are not properly represented. Experimental analyses are, therefore, widely used to underpin any work in this area. The most renowned model for predicting the damping resulting from air pumping is based on a significant quantity of experimental data and was generally developed and applied to high frequency vibrations of jointed or stiffened panels. This publication applies this model to low frequency panel vibrations by assessing the accuracy of the model for these systems. It is concluded that the theoretical model for high stiffness joints, although generally over approximating the damping magnitude, gives a good conservative estimate of the increase in damping due to air pumping for low frequency vibrations.
\end{abstract}

Keywords: damping, joints, modelling, metal panel

\section{INTRODUCTION}

In the current world of engineering, structural vibration problems continue to impact the design and construction of a wide range of products. The dynamics and sound transmission characteristics of structures are determined essentially by three parameters: mass, stiffness, and damping [1]. Damping controls the amplitude of the structural response at resonance and is responsible for the eventual decay of the free vibrations in any system and as such it is an important parameter to determine when attempting to predict the dynamic behaviour of a structure. To this day, damping is still the dynamic characteristic that is least understood and the most difficult to quantify.

A panel's total damping is generally due to several mechanisms that act simultaneously. These typically include material damping (mechanical hysteresis), dissipation at joints, interfaces, and supports, transport of energy to adjacent structures, and transport of energy to fluids in contact with the panel [2]. In order to accurately estimate the damping

${ }^{*}$ Corresponding author: Astronautics Research Group, University of Southampton, Southampton SO17 1BJ, UK. email: sjiw@soton.ac.uk of a given panel, it is therefore necessary to predict the contributions made by all mechanisms or at least the most significant and dominant mechanisms.

To date, decades of research in this area have produced a great wealth of knowledge. The mechanism of material damping has been extensively investigated [3-5], along with the transportation of structural vibration energy to adjacent media [6]. However, owing to the many possible variations inherent in structural joints and interfaces, this remains an area of considerable research activity $[\mathbf{7}, \mathbf{8}]$. It is well known that the boundary conditions of a structure are never as idealized as theories may suggest [9]. The central theoretical analysis for the prediction of joint damping of structural joints focuses on the property of air pumping, which was identified, through extensive experimental [10] and theoretical studies [11, 12], to be the dominant damping mechanism. This theoretical approach is based on empirical data and focuses on high-frequency vibration. It is the aim of this publication to determine its applicability to the low-frequency panel vibration analyses performed at the University of Southampton.

\section{JOINT DAMPING}

The problem of structural joint damping due to air pumping was studied in detail in the 1960s [10-12], 
the results of which have been published in more modern texts $[\mathbf{1}, \mathbf{2}]$. These early investigations studied the influence of stiffeners on the damping of metal panels and analysed many parameter permutations such as joint location, width, length, panel thickness, fastener spacing, bolt torque (over a limited range), and air pressure, identifying the critical parameter to be $d / \lambda_{\mathrm{B}}$, where $d$ is the fastener spacing and $\lambda_{\mathrm{B}}$ is the flexural wavelength of the panel [10]. The vast majority of this previous work focused on a $d / \lambda_{\mathrm{B}}$ magnitude greater than 0.25 , corresponding to high frequency vibrations (the exact magnitude of which is dependent on the longitudinal wave speed of the material). The central result of the previous analysis is the production of a graph displaying the damping result for all the test data in terms of normalized parameters. The core joint parameters are normalized with respect to reference values at $1 \mathrm{~atm}$ ambient pressure. These parameters are listed in Table 1 [2].

The damping value is quantified using the normalized version of the absorption coefficient denoted as the 'reduced absorption coefficient' $\gamma_{\mathrm{r}}$. For the values of $d / \lambda_{\mathrm{B}}$ investigated, there is a scatter of the results because of the many joint variations. However, for the purposes of a damping estimation, a moving average is also presented, which will be used to produce comparative theoretical data for the experimental tests outlined in this publication.

\section{EXPERIMENTAL APPROACH}

An experimental test campaign was carried out to measure the low-frequency damping of jointed panels and to compare these values with an equivalent monolithic panel and the results of the theoretical model.

\subsection{Test specimens}

The test panels were sized to be large enough to have a significant mass but small enough to be manageable for testing. It was also desirable to avoid square panels, reducing the likelihood of unusual symmetrical modes. Therefore, the ratio of length to height was chosen to be around 0.7. All the panels were cut from

Table 11 atm ambient pressure reference values

\begin{tabular}{|c|c|c|}
\hline \multirow{2}{*}{$\begin{array}{l}\text { Reference } \\
\text { parameter }\end{array}$} & \multicolumn{2}{|c|}{ Value } \\
\hline & Imperial units & Metric units \\
\hline Plate thickness, $h_{0}$ & $1 / 32$ in & $7.94 \times 10^{-4} \mathrm{~m}$ \\
\hline Fastener spacing, $d_{0}$ & 3 in & $0.0762 \mathrm{~m}$ \\
\hline $\begin{array}{l}\text { Longitudinal wave speed in } \\
\text { panel material, } c_{\mathrm{LO}}\end{array}$ & $2 \times 10^{5} \mathrm{in} / \mathrm{s}$ & $5080 \mathrm{~m} / \mathrm{s}$ \\
\hline Width of the joint, $w_{0}$ & 1 in & $0.0254 \mathrm{~m}$ \\
\hline
\end{tabular}
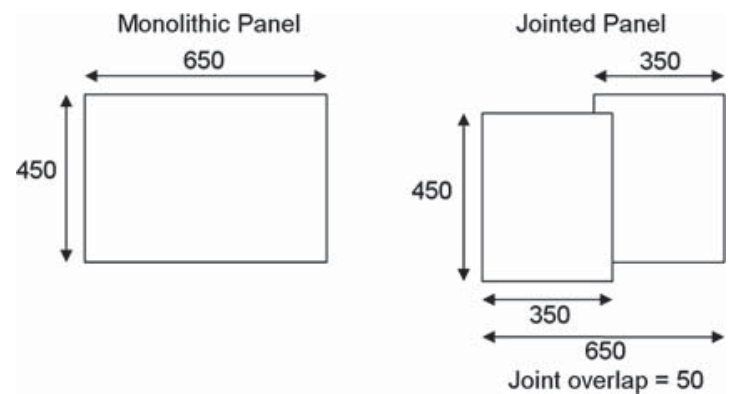

Fig. 1 Experimental panel layout (not to scale, all dimensions in $\mathrm{mm}$ )

a single sheet of 6082-T6 aluminium, with a thickness of $2 \mathrm{~mm}\left(E=70 \times 10^{9} \mathrm{~N} / \mathrm{m}^{2}\right.$ and $\left.\rho=2700 \mathrm{~kg} / \mathrm{m}^{3}\right)$. The exact dimensions of the panels and the initial joint specifications are displayed in Figs 1 and 2, respectively.

A total of six panels were constructed, one monolithic and five jointed, denoted as configurations $\mathrm{A}$ to F, respectively. The first two jointed panels (B and $\mathrm{C}$ ), constructed using the initial joint parameters as shown in Fig. 1, allow the effect of two different types of fasteners to be investigated, namely, bolts and rivets. The bolted panel also enabled the influence of bolt torque to be assessed for the low-frequency vibration. Configuration $\mathrm{D}$ reduces the distances between the fasteners $(d)$ to $20 \mathrm{~mm}$, and configurations $\mathrm{E}$ and $\mathrm{F}$ are used comparatively with $\mathrm{D}$ to assess the effect of the width of the joint overlap $(w)$. A summary of the panel configurations is displayed in Table 2.

\subsection{Test procedure}

Experimental tests were performed to determine the loss factors for the first 12 modes of each configuration (up to $\sim 170 \mathrm{~Hz}$ ), enabling a loss factor comparison based on the mode shape. The panels were initially suspended from two mounting points and excited using a pendulum-mounted impact hammer (as shown in Fig. 3(a)), allowing a high accuracy in the position of the excitation and repeatability.

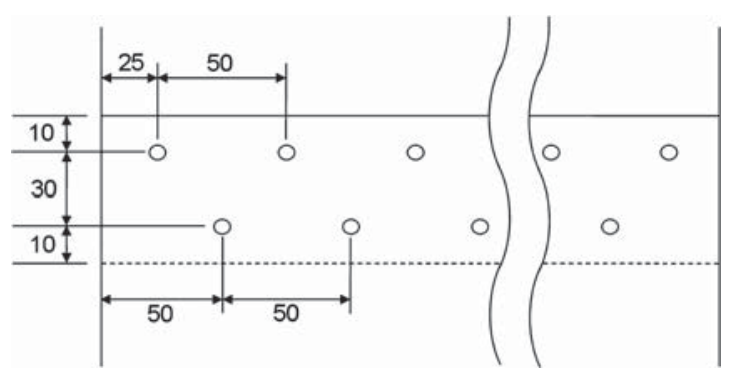

Fig. 2 Joint parameters (not to scale, all dimensions in $\mathrm{mm}$ ) 
Table 2 Summary of test configurations A-F

\begin{tabular}{|c|c|c|c|}
\hline Configuration & $\begin{array}{l}\text { General } \\
\text { description }\end{array}$ & $\begin{array}{l}\text { Overall panel } \\
\text { dimensions (mm) }\end{array}$ & $\begin{array}{l}\text { Joint } \\
\text { specifics }\end{array}$ \\
\hline A & $\begin{array}{l}\text { Monolithic } \\
\text { panel }\end{array}$ & $650 \times 450$ & $\mathrm{n} / \mathrm{a}$ \\
\hline B & Bolted joint & $650 \times 450$ & $\begin{array}{l}17 \text { fasteners ( } 50 \mathrm{~mm} \text { separation) } \\
\text { in two lines, } 30 \mathrm{~mm} \text { apart, } \\
50 \mathrm{~mm} \text { overlap }\end{array}$ \\
\hline $\mathrm{C}$ & Riveted joint & $650 \times 450$ & $\begin{array}{l}17 \text { fasteners ( } 50 \mathrm{~mm} \text { separation) } \\
\text { in two lines, } 30 \mathrm{~mm} \text { apart, } \\
50 \mathrm{~mm} \text { overlap }\end{array}$ \\
\hline $\mathrm{D}$ & Riveted joint & $650 \times 450$ & $\begin{array}{l}43 \text { fasteners ( } 20 \mathrm{~mm} \text { separation) } \\
\text { in two lines, } 30 \mathrm{~mm} \text { apart, } \\
50 \mathrm{~mm} \text { overlap }\end{array}$ \\
\hline E & Riveted joint & $650 \times 450$ & $\begin{array}{l}43 \text { fasteners ( } 20 \mathrm{~mm} \text { separation) } \\
\text { in two lines, } 20 \mathrm{~mm} \text { apart, } \\
40 \mathrm{~mm} \text { overlap }\end{array}$ \\
\hline $\mathrm{F}$ & Riveted joint & $650 \times 450$ & $\begin{array}{l}43 \text { fasteners ( } 20 \mathrm{~mm} \text { separation) } \\
\text { in two lines, } 40 \mathrm{~mm} \text { apart, } \\
60 \mathrm{~mm} \text { overlap }\end{array}$ \\
\hline
\end{tabular}

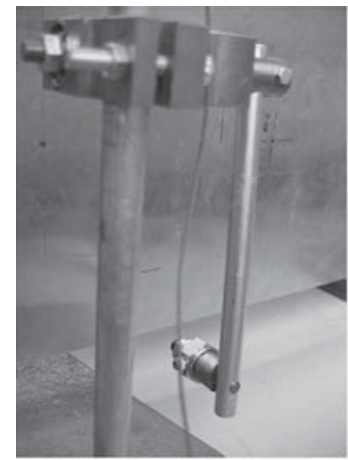

(a)

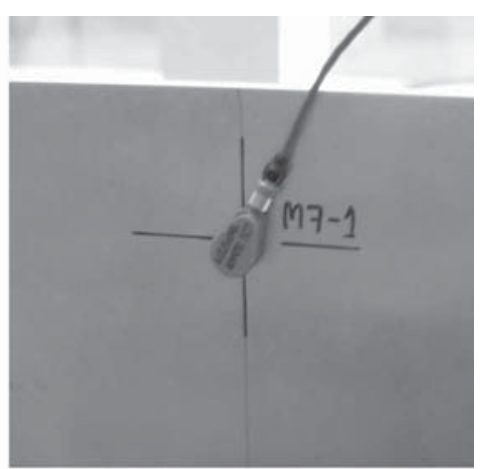

(b)
Fig. 3 Pendulum-mounted impact hammer and tear drop accelerometer

The resultant accelerations were measured using miniature tear drop-shaped accelerometers (mass of $0.6 \mathrm{~g}$ ), shown in Fig. 3(b). The signals from the accelerometers were captured on a computer at a sample rate of $5000 \mathrm{~Hz}$. Each vibration response was analysed using a sonogram [13], plotting time versus frequency, enabling the decay of each mode to be linearly interpolated. The decay results for each mode were then averaged, thus allowing the standard deviation of the data to be determined. The linearity of the damping was quantified using RSQ ( $R$-squared) values, which is the square of the Pearson product moment correlation coefficient [14]. The closer this value to 1 , the more linear the result. Initial tests were performed using both wax- and gluemounted accelerometers, and, as anticipated, it was found that for this frequency range, the method of accelerometer mounting had no significant effect on the measured damping magnitude. Wax was, therefore, used throughout the testing campaign as the accelerometers had to be moved frequently between the mounting points.

\subsection{External influences on the dynamics of the panel}

As the modal loss factors for metal plates (and especially aluminium plates) are known to be very low [1], any external influence on the panel's vibration will noticeably affect its damping and therefore the accuracy of the data. For vibration testing using an impact hammer, the external damping influence primarily comes from two sources: the support mounting of the panel and any added mass/attachments to the panel, i.e. accelerometers.

In order to perform the vibration tests, the panels were suspended from two points located along the larger panel edge. However, it was found that, as expected, for certain mode shapes, this resulted in large loss factor variability as the mounting points created another source of damping of the panel. To overcome this problem, the panels were mounted on the nodal points of each mode shape, thus minimizing the excitation of the mounting locations. A direct

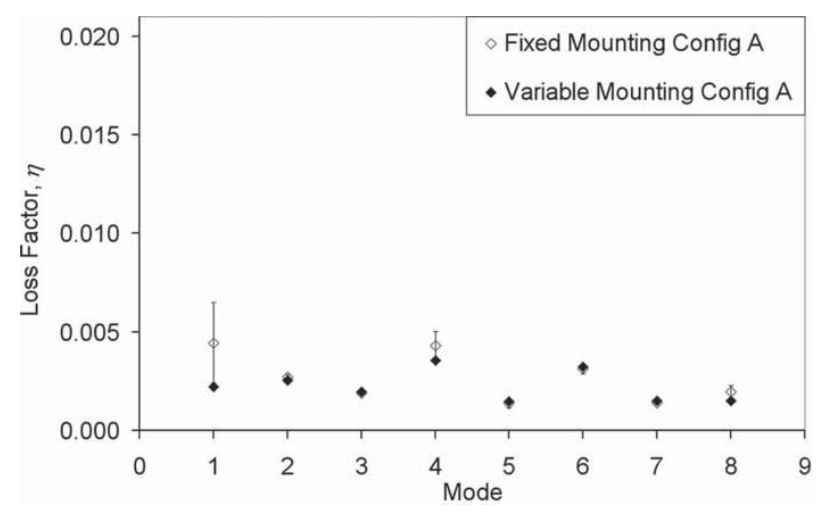

Fig. 4 Loss factors for fixed and variable mounting, configuration A 


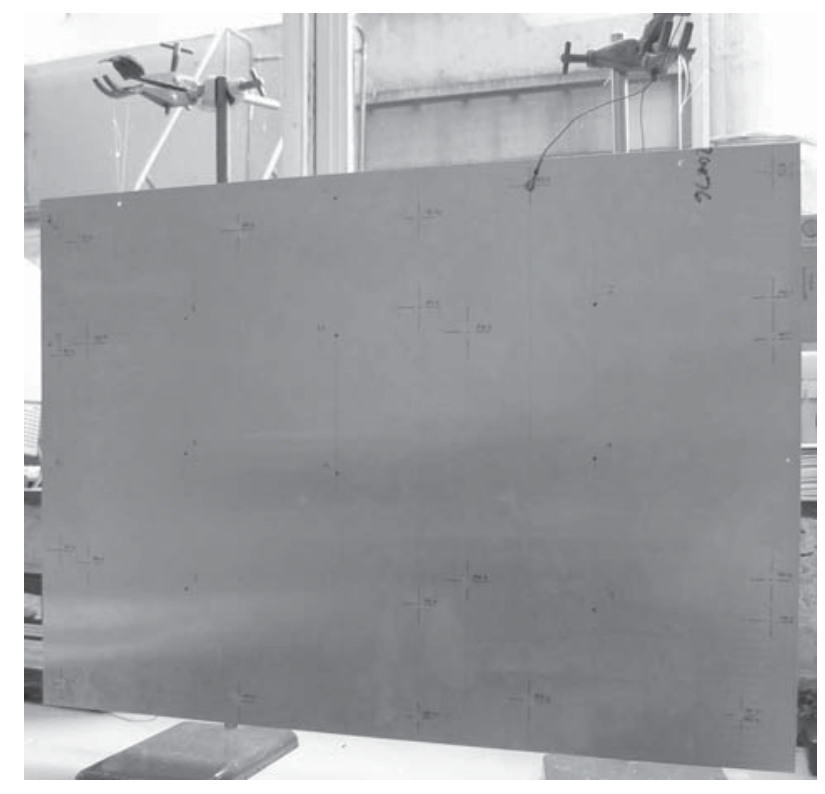

Fig. 5 Experimental setup for mode 7, configuration A

comparison of the loss factor data for each mounting condition is shown in Fig. 4 for configuration A. The fixed and variable mounting tests have average RSQ values of 0.940 and 0.995 , respectively, over the first eight modes.

It can be seen from the data that the loss factor variability (shown by the error bars measuring the standard deviation of the data) and magnitude
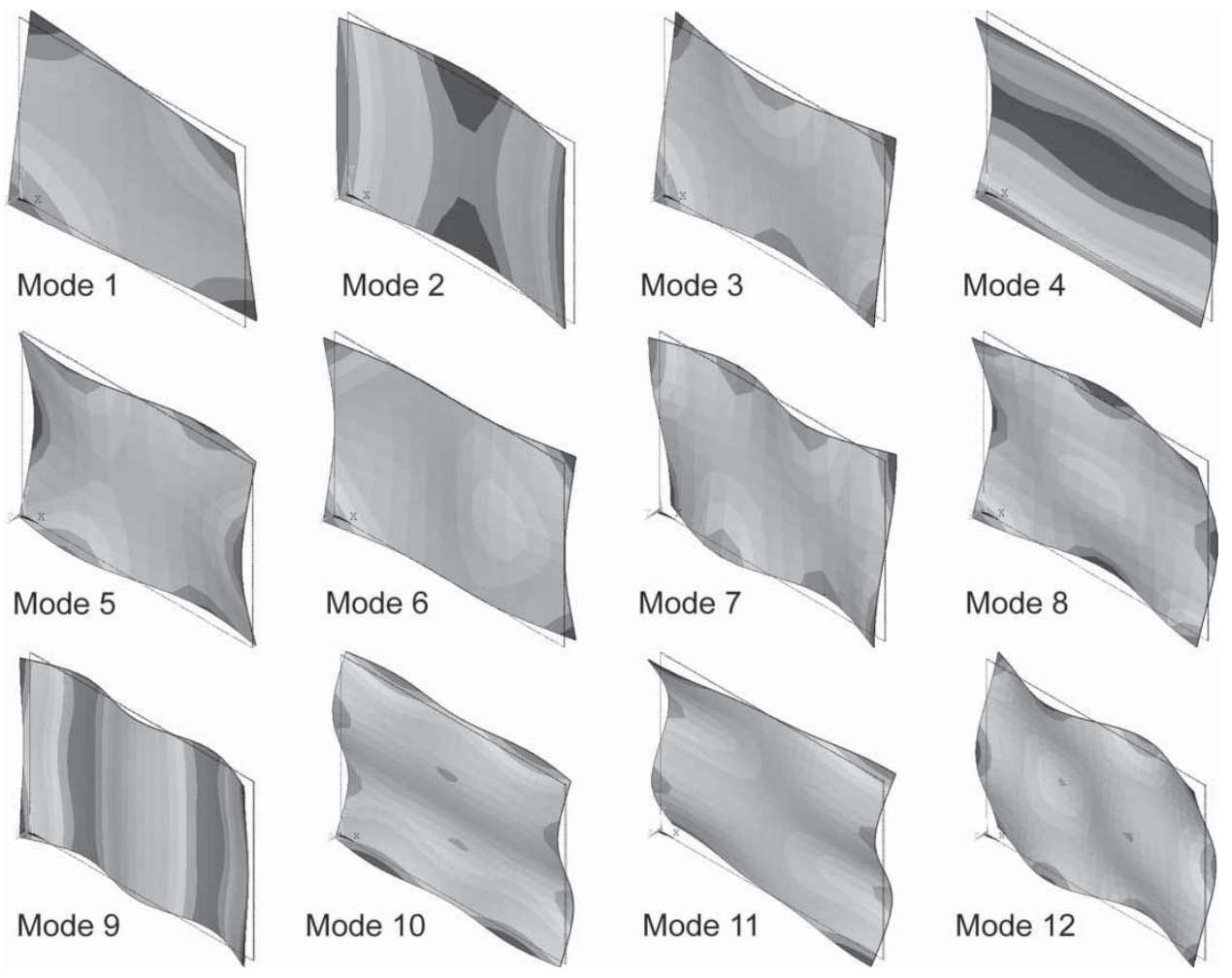

Fig. 6 General mode shapes 1 to 12 increase for the mode shapes that excite the mounting locations (i.e. mode shapes 1 and 4). For the remaining mode shapes, the loss factor change is insignificant, displaying the consistency of the data. As anticipated, the variable mounting condition is the most accurate method for determining the loss factors, a trend seen not only from the graph but also from the average RSQ values. However, the variable mounting test method is the most time-consuming method, as every panel must be suspended from different mounting points for every mode and configuration. From the point of view of the general application of this approach, it is also limited to panels that enable the complete flexibility required to suspend the specimen from any location.

From the initial tests performed, it was found that even the miniature accelerometers and connection cables had a noticeable influence on the damping magnitude when used in sufficient numbers. Four accelerometers were being used in the initial test case. It was, therefore, decided to use a single accelerometer to minimize this effect. Twenty-five hammer hits were applied, per mode, per configuration, and the resultant accelerations were measured at four antinode locations in turn using one accelerometer. For the number of permutations required, this resulted in 2400 hammer hits to obtain the complete data set. The experimental setup for mode 7 , configuration A is shown in Fig. 5, and the first 12 mode shapes are displayed in Fig. 6, which is theoretically determined using finite-element simulations in ANSYS 7.1. 


\section{THEORETICAL MODELLING AND RESULTS COMPARISON}

For the system under analysis, the ratio of $d / \lambda_{B}$ is very small (i.e. between 0.02 and 0.06 ), because of the low frequencies involved. For this range of values, the gradient of the moving average absorption coefficient curve based on empirical data tends to zero, resulting in the constant value for the reduced absorption coefficient $\gamma_{\mathrm{r}}$ of 0.01 . As this parameter is a constant, the value for the absorption coefficient is also a constant and is determined using equation (1) (as shown in reference [2])

$$
\gamma=\gamma_{\mathrm{r}}\left(\frac{w}{w_{0}}\right)
$$

From this parameter, the values of the plate-bending wavelength and the loss factor due to air pumping can be determined from the following equations

$$
\lambda_{\mathrm{B}}=(3 \pi)^{1 / 4} \sqrt{\frac{h c_{\mathrm{L}}}{f}}
$$

and

$$
\eta_{\text {air }}=\frac{\gamma L}{\pi^{2} S} \lambda_{\mathrm{B}}
$$

where $f$ is the frequency [2]

In using this theory, there are points that need to be highlighted to ensure its correct application. Equation (3) was derived based on a single line of fasteners and calculates only the damping resulting from air pumping. The joints studied experimentally (as shown by the general example in Fig. 1) have two lines of staggered fasteners. To account for this, the theory was applied, simulating the two staggered lines as one line with half the fastener spacing and the same joint width. For the purposes of this analysis, it is assumed that air pumping is the dominant source of damping. This assumption is based on previous investigations $[10,15]$, as stated in section 1 of this article. To correctly calculate comparative data, the loss factor from equation (3) is added to the average loss factor determined from the monolithic experimental result. The initial joint parameters used in the calculation process (for the experimental configurations B and C) are displayed in Table 3. The experimental and theoretical results for these configurations are shown in Fig. 7, where B is tested at three bolt torques: 1.5, 3, and $4.5 \mathrm{Nm}$.

From the initial inspection of the data shown in Fig. 7, it can be seen that, in general, the theoretical results correspond well with the stiffer joint experimental results, and the theoretical curve tends to form an upper bound of the damping for most of the mode
Table 3 Experimental joint parameters for theoretical analysis

\begin{tabular}{ll}
\hline Parameters & Experimental values \\
\hline Panel thickness, $h(\mathrm{~m})$ & 0.002 \\
Fastener spacing, $d(\mathrm{~m})$ & 0.025 \\
Wave speed in panel, $c_{L}(\mathrm{~m} / \mathrm{s})$ & 5080 \\
Joint width, $w(\mathrm{~m})$ & 0.05 \\
Joint length, $L(\mathrm{~m})$ & 0.45 \\
Panel area, $S\left(\mathrm{~m}^{2}\right)$ & 0.2925 \\
Average monolithic panel loss factor & 0.00204 \\
$\quad$ (configuration A), $\eta_{\text {mon }}$ & \\
\hline
\end{tabular}

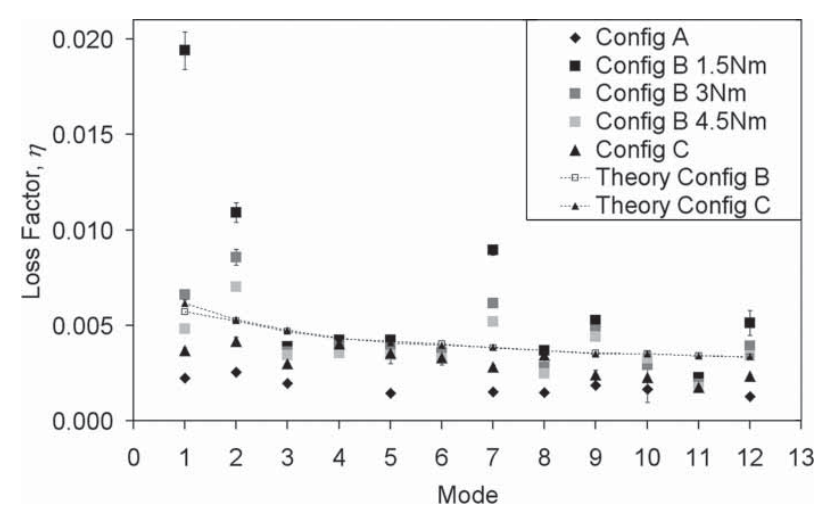

Fig. 7 Comparative loss factor results for configurations A, B, and C

shapes. Exceedences of the theoretical magnitudes occur for modes 1, 2, 7, 9, and 12, and this discrepancy increases as the stiffness of the joint reduces. It should also be noted that the damping for these modes is much more sensitive to a change in the joint stiffness. This will be discussed further in the following section. Another point that can be observed from Fig. 7 is that there is very little variation between the theoretical values. This is due to the input joint parameters being the same. The only variation is due to the frequency changes in the equivalent mode shapes, and this has a noticeable effect on theoretical data for mode 1 .

The data that compare the effect of $d$, the distance between fasteners, are shown together with those for configuration A in Fig. 8. The increase in the stiffness of the joint as a result of the increase in the number of fasteners seems to result in no consistent trend of the experimental data. However, the theoretical result now represents the upper magnitude boundary for all the loss factor data and as such would seem to be a very good conservative estimation of the damping due to the presence of the joint for these low frequency vibrations.

It has been identified by previous work [2] that the damping contributed to a panel by a multi-pointfastened joint is at least approximately proportional to the overlap width $(w)$ of the joint. However, the dominant trend from the experimental data shown in Fig. 9 (most noticeably for modes 1,2 , and 5 ) is that there is 


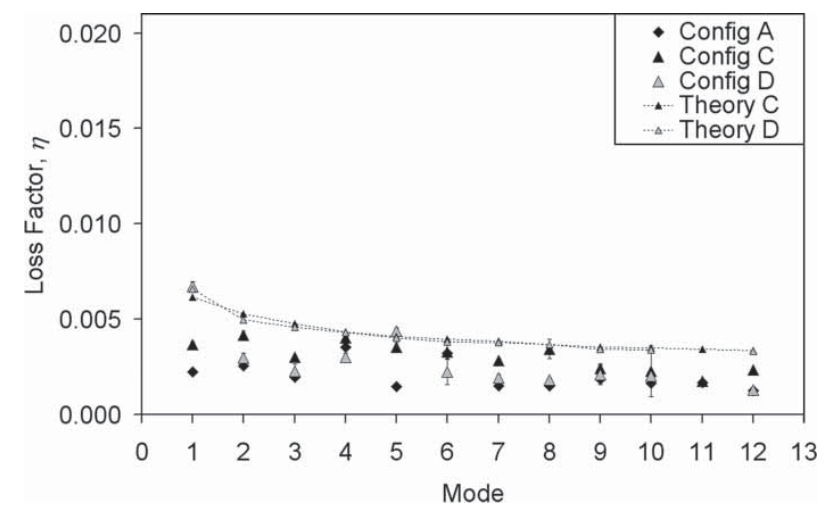

Fig. 8 Comparative loss factor results for configurations A, C, and D

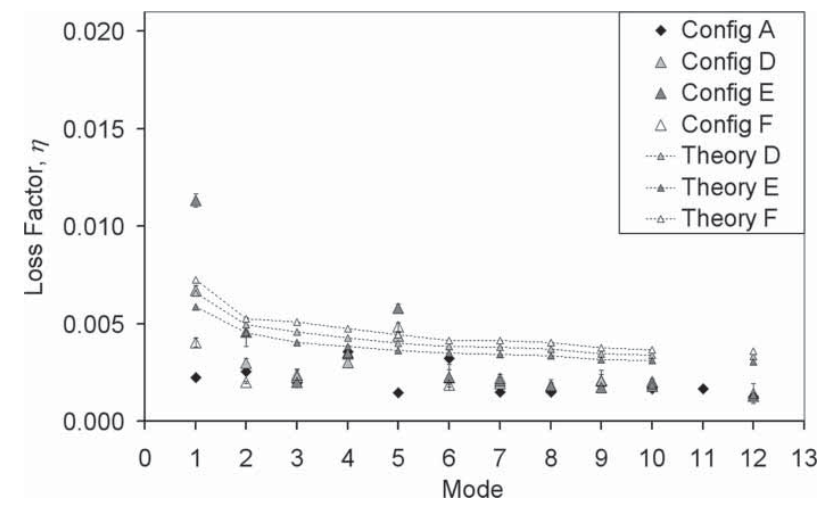

Fig. 9 Comparative loss factor results for configurations A, D, E, and F

an increase in the damping as $w$ reduces. This can be ascribed to the effect of the two bolt lines. The spacing between the lines was increased as the overlap was increased, resulting in a stiffness change of the joint. The damping data trend shown in Fig. 9 is, therefore, not dominated by overlap but by stiffness. As such, configuration E, with the lowest stiffness, is found to have the greatest damping magnitudes, and vice versa for configuration F. It can, therefore, be concluded that the theory, developed for tight joints, does simulate these configurations well. This suggests that either the model is a very conservative approximation of the air pumping, or air pumping for these frequencies is the dominant source of damping.

\section{FURTHER INVESTIGATIONS}

As a further insight into these data, an investigation was performed to determine why the damping magnitudes for some mode shapes exceeded the theoretical model predictions (most notably shown in Fig. 7). Finite-element analysis simulations were performed in parallel to the experimental campaign to aid the identification of the mode shapes. These were performed using ANSYS 7.1, and the models were created using SHELL63 and SHELL91 elements for the monolithic and jointed panels, respectively [16]. An element size of $25 \mathrm{~mm}$ was used for the monolithic simulation. The number of elements was increased for the jointed model (using an element size of $10 \mathrm{~mm}$ ) to increase the number of possible constraints along the width and length of the joint.

Initial trial simulations were performed using contact elements to simulate the plate joints. However, this form of simulation disallows the use of the modal analysis method, significantly increasing the difficulty in obtaining the modal solution of the problem. Therefore, as these models were only intended to be an approximate guide for mode shape and frequency comparisons, more simplistic simulations were run. These were performed by two different models, the first incorporated a joint where all the nodes were merged. The second incorporated a joint where half the nodes were merged together. The displacements of the panel along the joint edge positions were output from ANSYS and plotted from the view direction shown in Fig. 10. The joint edge displacements for all of the first 12 modes are shown in Fig. 11.

From these data, certain modal trends can be found, thereby grouping the mode shapes together in relation to how these displacements affect the joint. First, modes 1 and 7 and to a lesser extent, modes 11 and 12, all display sharp opposing displacements across the joint. These mode shapes, along with modes 2 and 9 (the longitudinal displacement modes), all actively open the joint. The effect of this can be clearly seen in Fig. 7, resulting in high damping magnitude sensitivity with respect to the joint stiffness. The only exception to this is mode 11 , and this is due to low excitation levels around the joint edges. As the damping magnitude increase is shown to be related to the joint being opened, it can be ascribed to an increased effect of air pumping. The data for mode 5 suggest consistently high damping values, exceeding the theoretical model shown in Fig. 9. However, although the magnitude is shown to be higher in Fig. 7, the reduction in stiffness

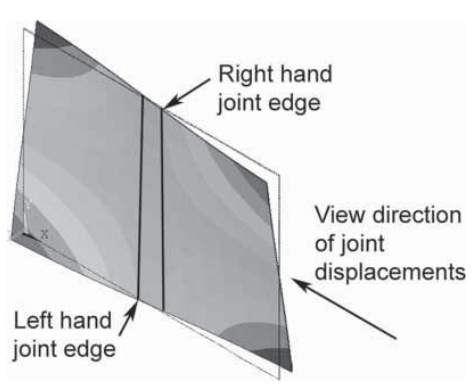

Fig. 10 View direction of joint displacements 


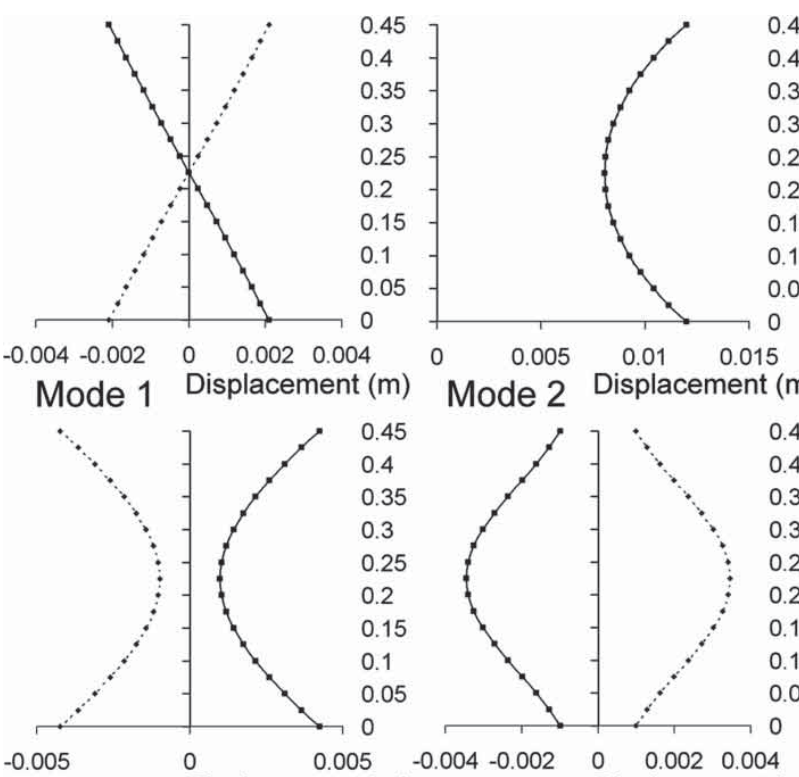

Mode 5 Displacement $(\mathrm{m})$

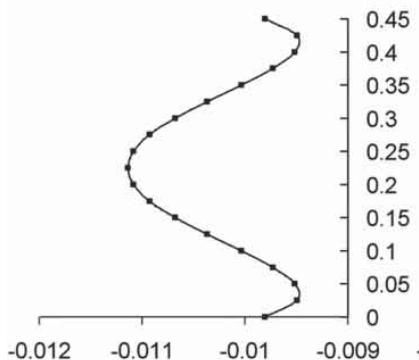

$\begin{array}{llll}-0.012 & -0.011 & -0.01 & -0.009\end{array}$

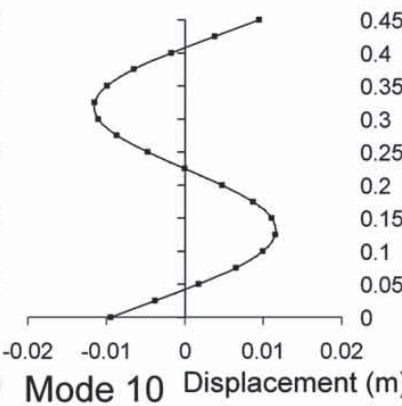

Mode 6

- Left Hand Joint Edge

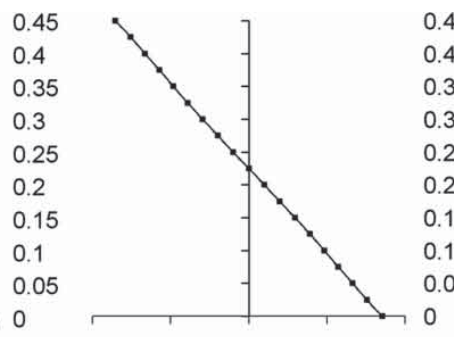

$\begin{array}{llllllllll}-0.02 & -0.01 & 0 & 0.01 & 0.02 & -0.02 & -0.01 & 0 & 0.01 & 0.02\end{array}$

Mode 3 Displacement $(\mathrm{m})$ Mode 4 Displacement $(\mathrm{m})$
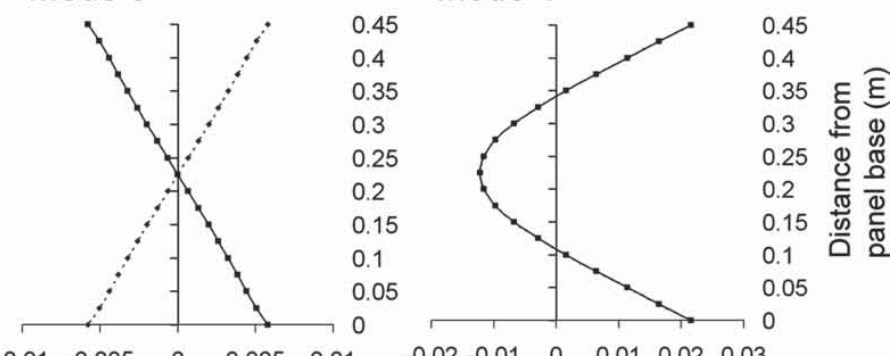

Mode 7 Displacement $(\mathrm{m})$ Mode 8 Displacement $(\mathrm{m})$

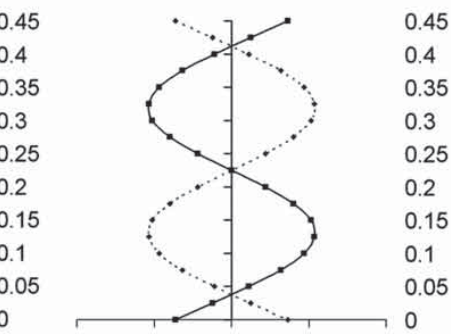

$\begin{array}{lllll}-0.004 & -0.002 & 0 & 0.002 & 0.004\end{array}$

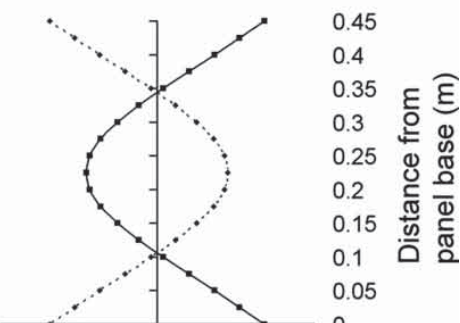

Fig. 11 Simulated joint edge displacements

does not result in a notable damping increase, suggesting the presence of other damping mechanisms for this mode shape.

\section{CONCLUSIONS}

It has been observed from previous research [2] that the damping produced by multi-point-fastened joints markedly depends on the wavelength $\lambda_{B}$ of flexural waves on the panel of concern. If the wavelength is smaller than the fastener spacing, then gapping can occur between them. However, it has been identified in this investigation that much longer wavelengths can result in notable air pumping effects, which are very sensitive to joint stiffness reductions. These are due to specific mode shapes that open the joint edges. It was also determined that for the higher stiffness joints, the theoretical model tended to over approximate the damping, an effect that can be ascribed to the two fastener lines (as opposed to the theoretically modelled single fastener line). This increases the stiffness of the joint and thus reduces the effects of air pumping. However, despite these inaccuracies, the magnitude and general trend of the theoretical data are a good approximation for the high stiffness joints vibrating at low frequencies.

\section{REFERENCES}

1 Ungar, E. E. Noise and vibration control engineering: principles and applications, 1992 (John Wiley and Sons, Inc., Hoboken, NJ, USA).

2 Ungar, E. E. Damping of panels due to ambient air. In Damping applications in vibration control (Ed. P. J. Torvik), AMD-vol. 38, 1980, pp. 73-81 (American Society of Mechanical Engineers, New York).

3 Lazan, B. J. Damping of materials and members in structural mechanics, 1968 (Pergamon Press, New York).

4 Snowdon, J. C. Vibration and shock in damped mechanical systems, 1968, ch. 1 (John Wiley \& Sons, Inc., New York).

5 Goodman, L. E. Material damping and slip damping. In Shock and vibration handbook (Eds C. M. Harris and 
C. E. Crede), 2nd edition, 1976, ch. 36 (McGraw-Hill Book Co., New York).

6 Cremer, L., Heckl, M., and Ungar, E. E. Structure-borne sound, 1973 (Springer-Verlag, New York).

7 Phani, S. A. Damping identification in linear vibration. PhD Thesis, St John's College, Cambridge, 2004.

8 Salzmann, A., Fragomeni, S., and Loo, Y. The damping analysis of concrete beams under free vibration. Adv. Struct. Eng., 2003, 6(1), 53-64.

9 Aglietti, S. and Cunningham, P. R. Is a simple support really that simple? J. Sound Vibr., 2002, 257(2), 321-335.

10 Ungar, E. E. and Carbonell, J. R. On-panel vibration damping due to structural joints. AIAA J., 1966, 4(8), 1385-1390.

11 Maidanik, G. Energy dissipation associated with gas pumping in structural joints. J. Acoust. Soc. Am., 1966, 40(5), 1064-1072.

12 Ungar, E. E. and Maidanik, G. High frequency plate damping due to gas pumping in riveted joints. J. Acoust. Soc. Am., 1963, 44(1), 292-295.

13 Hodges, C., Power, J., and Woodhouse, J. The use of the sonogram in structural acoustics and an application to the vibrations of cylindrical shells. J. Sound Vibr., 1985, $101(2), 203-218$.

14 Hays, S. An outline of statistics, 6th edition, 1962 (Longmans, Harlow, UK).

15 Wylie, A. Vibration damping in structural joints. Fourth Year Project, University of Cambridge, 1997/1998.
16 Moaveni, S. Finite element analysis: theory and application with ANSYS, 1999 (Prentice Hall, Upper Saddle River, New Jersey, USA).

\section{APPENDIX}

\section{Notation}

$c_{\mathrm{L}}, c_{\mathrm{Lo}} \quad$ longitudinal wave speed of the panel

and reference wave speed, respectively

$d, d_{0} \quad$ joint fastener spacing and reference spacing, respectively

E Young's modulus

$F \quad$ frequency

$h, h_{0} \quad$ plate and reference thicknesses, respectively

$L \quad$ length of the joint

$S \quad$ panel area

$w, w_{0} \quad$ joint width and reference width, respectively

$\gamma, \gamma_{\mathrm{r}} \quad$ absorption coefficient and reduced absorption coefficient, respectively

$\begin{array}{ll}\eta & \text { loss factor } \\ \eta_{\text {air }} & \text { loss factor due to air pumping }\end{array}$

$\eta_{\text {mon }} \quad$ loss factor from monolithic panel

$\lambda_{B} \quad$ flexural wavelength of the panel

$\rho \quad$ density 